\title{
Trace Level Cyclic Voltammetry Facilitated by Single Walled Carbon Nanotube Network Electrodes
}

Paolo Bertoncello, Jonathan P. Edgeworth, Julie V. Macpherson" and Patrick R. Unwin*, Department of Chemistry, University of Warwick, Coventry CV4 7AL

\section{Supporting Information 1: Materials}

(Ferrocenylmethyl)trimethylammoniumhexafluorophosphate, $\quad\left(\mathrm{FcTMA}^{+} \mathrm{PF}_{6}^{-}\right)$, was obtained by metathesis of (ferrocenylmethyl)trimethylammoniumiodide (FcTMA ${ }^{+}{ }^{-}$, Strem Chemical Co.) following a procedure reported elsewhere. ${ }^{1} \mathrm{NaCl}$ (Trace Select $^{\mathrm{TM}}$, purity $\geq 99.99 \%$ ), and dopamine hydrochloride were purchased from Sigma and used as received. Acetic acid/acetate buffer ( $0.1 \mathrm{M}$ acetate) was prepared from sodium acetate and acetic acid. All aqueous solutions were prepared from Milli-Q reagent water (Millipore Corp.) with a resistivity $\geq 18 \mathrm{M} \Omega \mathrm{cm}$ at $25^{\circ} \mathrm{C}$.

[1] Szentirmay, M.N.; Martin, C.R. Anal. Chem. 1984, 56, 1898

Supporting Information 2: $\log$ Concentration versus log peak oxidation plot for $\underline{\text { the electrochemical detection of FcTMA }}{ }^{+}$

Cyclic voltammograms (CVs) were recorded using an electrochemical analyzer $(\mathrm{CH}$ Instruments, model CHI730A). A typical two electrode configuration was used, where the working electrode was a SWNT network contacted via a gold band and an $\mathrm{Ag} / \mathrm{AgCl}$ wire $(0.1 \mathrm{M} \mathrm{NaCl})$ served as the reference electrode. When $10 \mu \mathrm{L}$ of solution was placed on the SWNT network, the area of the working electrode was 
constant $\left(\sim 0.125 \mathrm{~cm}^{2}\right)$ for all measurements during the timescale of a set of $\mathrm{CV}$ measurements.

Figure S1 shows a plot of the logarithm of the anodic peak current versus the logarithm of the concentration of FcTMA ${ }^{+}$at a SWNT network for concentrations in the range $25 \mathrm{nM}$ to $5 \mu \mathrm{M}$. In accordance with the Randles Sevcik equation ${ }^{2}$ (eq 1) which predicts the peak current, $i_{\mathrm{p}}$, resulting from planar diffusion to an electrode of area, $A$ :

$$
i_{\mathrm{p}}=\left(2.69 \times 10^{5}\right) n^{3 / 2} A D^{1 / 2} C v^{1 / 2}
$$

where $n$ is the number of electrons transferred per redox event, $D$ and $C$ are the diffusion coefficient and concentration of the redox species of interest and $v$ is the potential scan rate, the peak current is linear with concentration in the range $25 \mathrm{nM}$ to $5 \mu \mathrm{M}$.

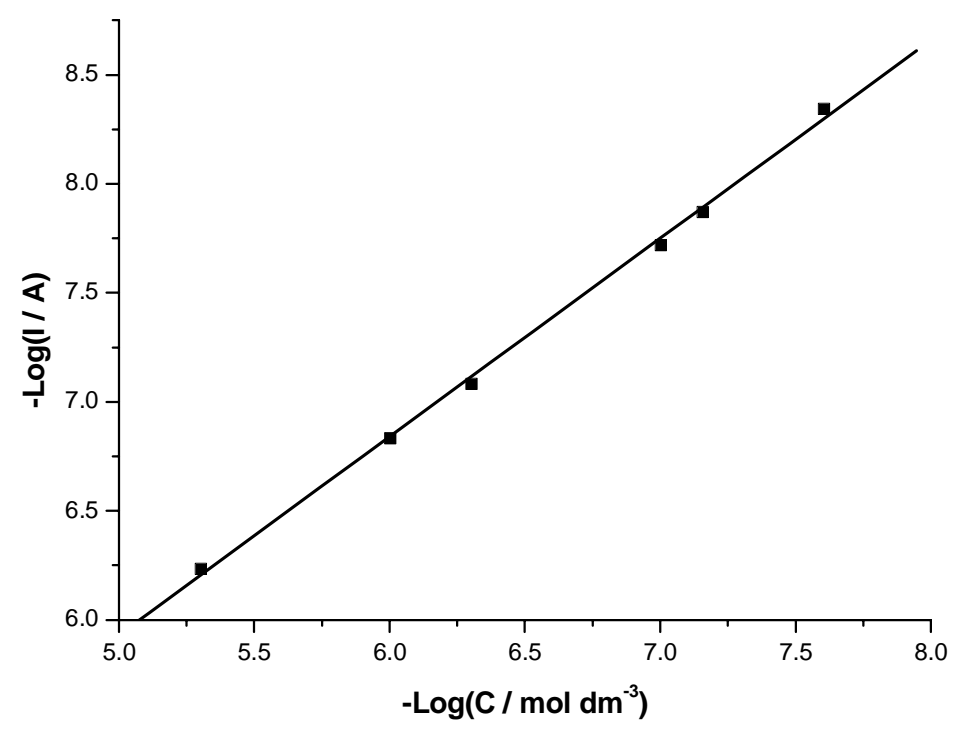

S1. Plot of the logarithm of the anodic peak current versus the logarithm of FcTMA ${ }^{+}$ concentration, for the oxidation of $\mathrm{FcTMA}^{+}$at varying concentrations in the range 25 $\mathrm{nM}-5 \mu \mathrm{M}$ at a SWNT network electrode. The potential scan rate was $0.1 \mathrm{~V} \mathrm{~s}^{-1}$ and $\mathrm{NaCl}$ served as the supporting electrolyte at a concentration of $0.1 \mathrm{M}$. 
[2] Bard, A.J.; Faulkner, L.R. Electrochemical Methods: Fundamental and Applications, $2^{\text {nd }}$ ed.; J. Wiley \& Sons: New York, 2000

Supporting Information 3: Peak current - scan rate characteristics for the electrochemical oxidation of $100 \mathrm{nM} \mathrm{FcTMA}^{+}$

$\mathrm{S} 2$ shows a plot of peak current density versus scan rate ${ }^{1 / 2}$ (over the scan range 0.05 $2 \mathrm{~V} \mathrm{~s}^{-1}$ ) for the oxidation of $100 \mathrm{nM} \mathrm{FcTMA}^{+}$.

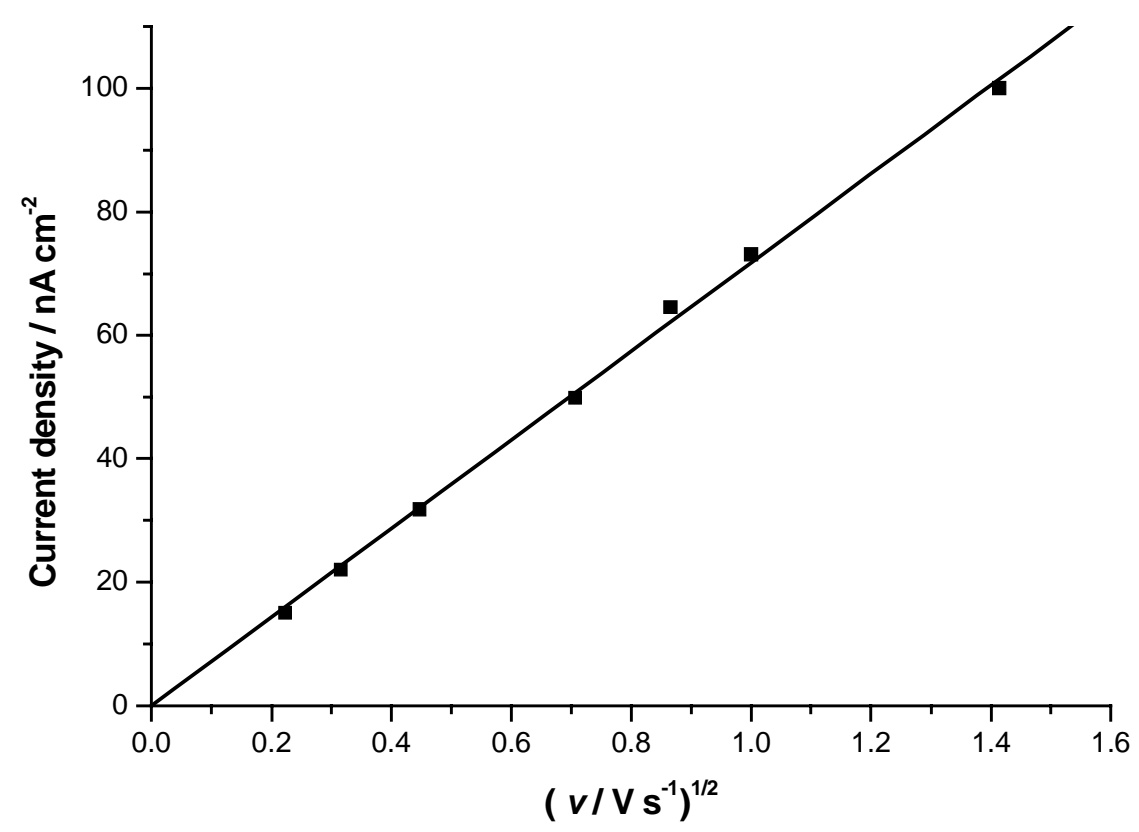

S2. Plot of the anodic peak current density versus square root of the scan rate for the oxidation of FcTMA ${ }^{+}(100 \mathrm{nM})$ at a SWNT network electrode 